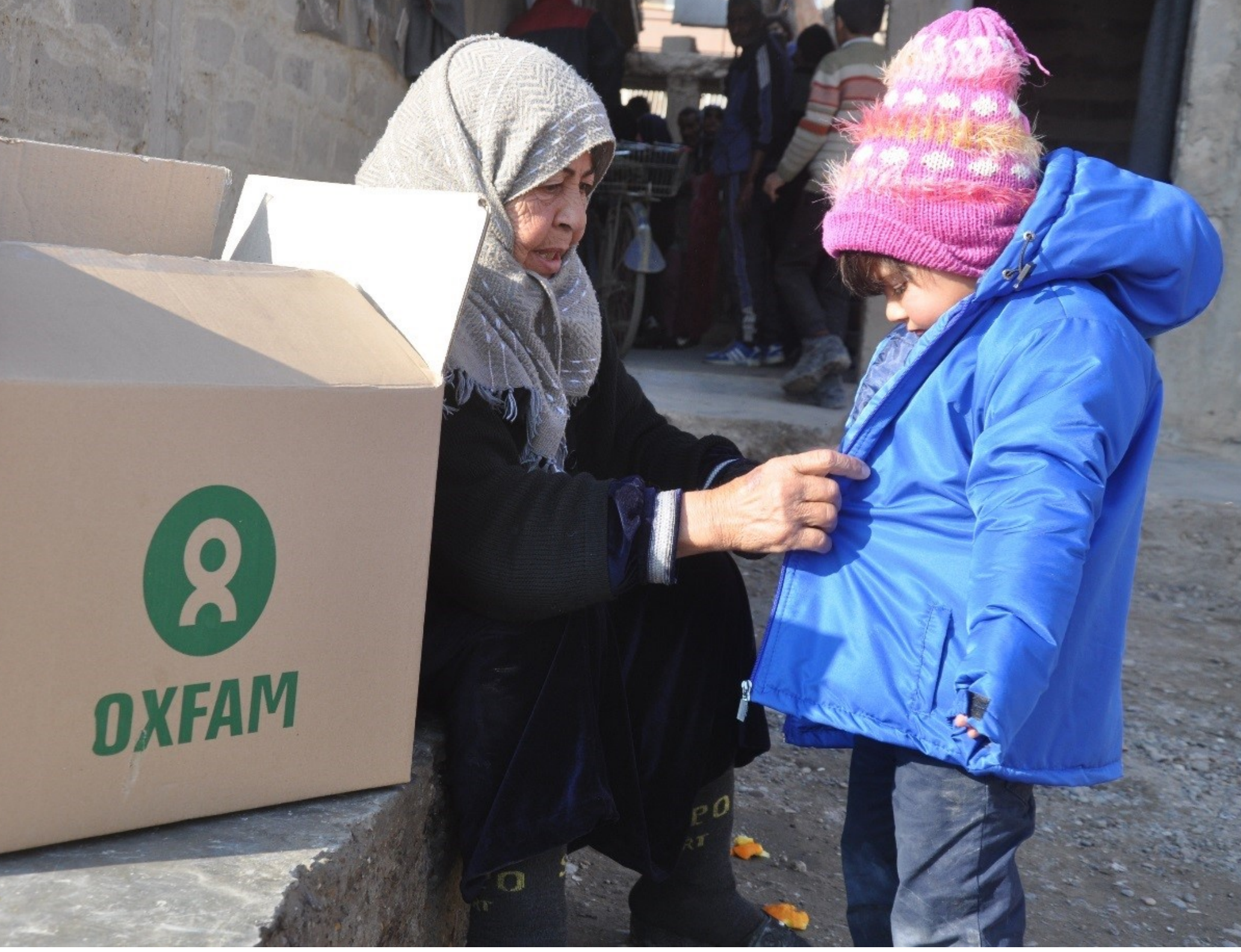

\title{
GENDER PERSPECTIVES \\ ON HUMANITARIAN \\ PROGRAMMING IN \\ SYRIA
}


Delivering aid in a conflict setting is complex and often frustrating. Oxfam has been delivering humanitarian aid in response to the conflict in Syria for a number of years, but there are still access restrictions that limit capabilities. Deir ez-Zor in eastern Syria is particularly hard to reach, and there are a large number of displaced people returning to an area severely affected by the collapse of markets and public services. Due to a number of factors women are shouldering an increasing number of responsibilities, both within and outside the home. This case study examines how conducting a remote assessment that takes gender into consideration can benefit aid distribution.

(C) Oxfam International September 2018

This case study was written by Zorica Shakun and Tammam Sbeih. Oxfam acknowledges the assistance of Moutaz Adham; Ines Smith; Jennifer McAteer; the Syria country programme and support teams; Eleanor Parker; Jude Powell; and Shekhar Anand in its production. It is part of a series of papers written to inform public debate on development and humanitarian policy issues.

For further information on the issues raised in this paper please email Zorica Shakun (ZSkakun@oxfam.org.uk) or Tammam Sbeih (TSbeih@Oxfam.org.uk).

This publication is copyright but the text may be used free of charge for the purposes of advocacy, campaigning, education, and research, provided that the source is acknowledged in full. The copyright holder requests that all such use be registered with them for impact assessment purposes. For copying in any other circumstances, or for re-use in other publications, or for translation or adaptation, permission must be secured and a fee may be charged. Email

policyandpractice@oxfam.org.uk.

The information in this publication is correct at the time of going to press.

Published by Oxfam GB for Oxfam International under

ISBN 978-1-78748-331-6 in September 2018.

DOI: $10.21201 / 2018.3316$

Oxfam GB, Oxfam House, John Smith Drive, Cowley, Oxford, OX4 2JY, UK.

Cover photo: Winterization kit distribution in Deir ez-Zor, Syria. Photo: Dania Kareh/Oxfam. 


\section{BACKGROUND AND INTRODUCTION}

The conflict in Syria that started in 2011 is now a complex and protracted multi-sided civil war. In 2017, 69\% of the Syrian population was estimated to be living in extreme poverty, compared to $34 \%$ before the crisis. ${ }^{1}$ Such impoverishment is due to large-scale population movements, widespread destruction of agriculture and markets, and the depletion of productive assets and savings, all of which have dramatically limited access to food.

Oxfam has been delivering humanitarian aid in Syria since 2013, focusing largely on water, sanitation and hygiene (WASH), with some work promoting public health. Oxfam has assisted an estimated 2.5 million people across 10 of Syria's 14 governorates, in areas held by both the government and the opposition.

Deir ez-Zor District in eastern Syria is considered a hard-to-reach area for humanitarian actors. As of August 2018, more than 250,000 people were displaced from or within Deir ez-Zor governorate. Around 15,000 have returned -this figure is expected to increase. However, conditions are still not in place for the safe, dignified and sustainable return of most of these internally displaced people. ${ }^{2}$ The area has until very recently been reliant on UN air drops of food, medicine and other supplies. There is a high risk of malnutrition, especially among pregnant and nursing women and their children. ${ }^{3}$ Oxfam had not previously worked in the governorate of Deir ez-Zor because it was controlled and besieged by ISIS militants until late 2017.

As a result of the conflict, many women have taken on the role of principal breadwinners for their families, as men are killed, disappear, flee the country or focus on fighting. Women are therefore increasingly assuming responsibilities outside the home, even though they still shoulder the burden of household chores. ${ }^{4}$ Households with a female main income provider have less access to aid and resources for a number of reasons, including a lack of information and risks associated with women leaving their homes. Additionally, the conflict has given rise to property and land grievances, such as in areas of spontaneous settlement, and where displaced families have settled in the vacated homes of other displaced people. Women's limited ability to negotiate solutions in the current context can deprive them of their rights to property and long-term security. ${ }^{5}$

Through the Emergency Food Security and Vulnerable Livelihoods intervention in Deir ez-Zor, Oxfam is aiming to address the immediate basic needs of the local population, ${ }^{6}$ while simultaneously positioning itself in the area as a reliable actor for longer-term work on resilience, including more explicit work on economic and gender justice. 
A longer-term vision for our economic and gender justice work in Syria has been discussed with the Syrian communities already working with Oxfam, in order to understand their needs, capacities and aspirations. ${ }^{7}$ Transformation in women's livelihoods is central to this strategy, both to satisfy immediate needs and as an opportunity for long-term change in gender relations, because it is evident that gender roles are already shifting due to the conflict and humanitarian crises.

\section{THE PROGRAMME}

In this complicated context, Oxfam wanted to be able to provide aid to affected communities in Syria for which entry points and information were limited. Aware of the changing gender dynamics across the country, Oxfam embarked on an approach that was embedded in strong relationships with government bodies and non-governmental partners in order to meet communities' needs, and boost their capacities and aspirations.

Based on internal analysis and scenario planning, Oxfam decided to scale up and respond to critical needs in Deir ez-Zor. A multi-sector assessment identified humanitarian needs in WASH, food security, livelihoods, shelter, education, protection and gender. Oxfam will be able to implement programmes through local partners in a number of governorates, including Deir ez-Zor, Homs, Hama and Rural Damascus, to build capacity and contribute to the localization of aid.

\subsection{BUILDING RELATIONSHIPS}

Formal discussions with the Ministry of Social Affairs and Labour and the Ministry of Foreign Affairs were a crucial first step towards developing a strategy to support the immediate and longer-term needs of affected communities.

Being able to establish local partnerships has been a significant advantage, making Oxfam one of only two humanitarian aid providers in Deir ez-Zor (the other being the Syrian Arab Red Crescent).

The Oxfam-facilitated consultation was attended by international NGOs including Danish Refugee Council, Norwegian Refugee Council, International Medical Corps, Medair, Action Against Hunger, Adventist Development and Relief Agency, and Terre des Hommes Italy, as well as local organizations operating in Deir ez-Zor, such as Al-Birr and Social Services. Initial and rapid needs assessments conducted by local NGOs prior to the consultation were shared, helping to identify the necessary immediate and medium-term interventions. As part of the preliminary discussions for the consultation, multi-sectoral response coordination systems for governorates and sectors were agreed between NGOs. 


\subsection{NEEDS ASSESSMENT}

Due to severe access restrictions, Oxfam used a number of indirect methods to assess the needs of people requiring assistance in Deir ezZor. These included informal observations and conversations with communities, the use of secondary open sources (such as the UN OCHA Humanitarian Needs Overview $2018^{\circ}$ and a World Food Programme revie $^{9}$ ), and frequent remote interactions between Oxfam local teams and technical advisors in regional offices such as Amman and Beirut, and in the UK Oxfam headquarters.

In addition, Oxfam drew on an assessment carried out by Al-Birr and Social Services in December 2017 and January 2018 which reported on the capacity of local actors currently delivering aid and current implementation modalities. Social Services employs around 300 people (of whom around half are women), and works with 700 volunteers (60\% of whom are women).

\subsection{KEY ACHIEVEMENTS}

Oxfam used the findings of the needs assessment to begin providing appropriate, timely and gender-sensitive support. The assessment created access channels to restricted areas and provided much-needed information on specific localized needs: it has influenced the distribution of bread bundles and winterization kits for women and men reflecting gender sensitivity. These distributions have been delivered through seven centres run by field staff and volunteers.

Additionally, Oxfam demonstrated agility and perseverance in setting up agreements with the governmental bodies and the local partner in order to respond to the immediate needs of people in Deir ez-Zor. These provide strong foundations for enduring partnerships. Careful interactions with partners have enhanced Oxfam's reputation among the population and are helping to build trust between Oxfam and state institutions, which is essential for continuing the work and undertaking development programmes in future.

\section{WHAT DID WE LEARN?}

\subsection{WHAT WORKED WELL?}

The gradual building of relationships with partners in the assessment process was of benefit to the programme, helping Oxfam to gain trust within communities. It also provided Oxfam with the ability to quickly learn of and react to imminent threats, such as physical attacks against people receiving assistance and staff, or destruction of assets (vehicles, distribution kits, etc.). 
Distributions are essential to the survival and well-being of populations severely affected by long-term conflict and displacement, and the findings from the assessment contributed to decisions on distribution modalities, such as having safe spaces and multiple supervisors present. The presence of male and female supervisors and volunteers reflected concern for fairness in access to aid, and for the protection of the safety and dignity of women waiting in the queues.

Photo: A family at a distribution in Deir ez-Zor. Credit: Dania Kareh/Oxfam.

\subsection{WHAT DID NOT WORK WELL?}

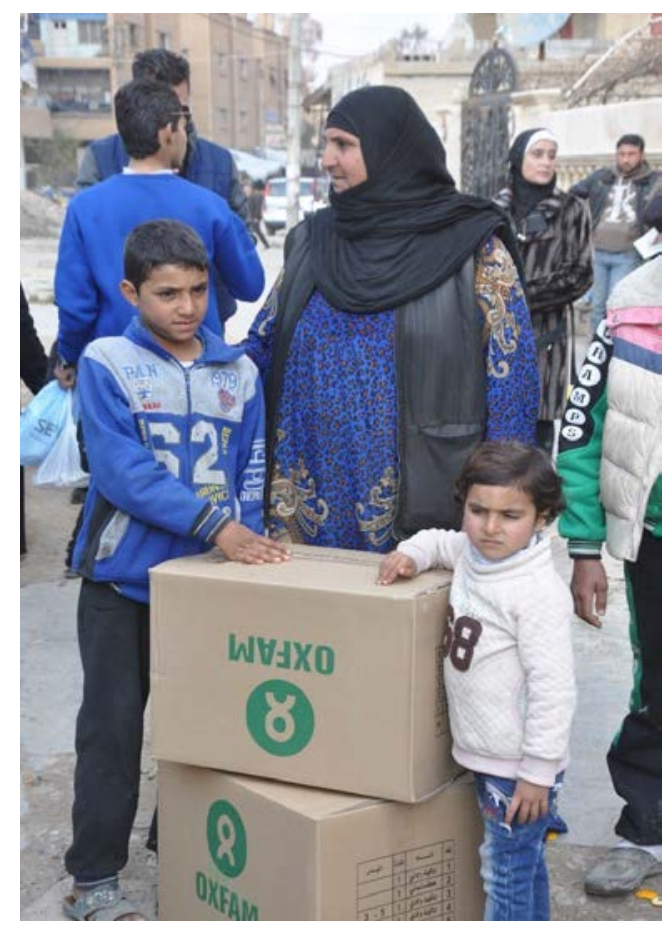

Access restrictions meant that it was difficult to collect feedback and accurate data from people receiving assistance. It was not possible to precisely monitor the appropriateness of the intervention, its impact or the impartiality of the benefits in practice. For example, it took some time for the Oxfam team to receive feedback from people they were assisting that black winter jackets had been rejected, as they reminded many people of mourning for lost loved ones. Lighter colours were requested and distributed instead.

Gender analysis was conducted remotely, relying on existing secondary information collected by other actors. This was helpful in understanding the general landscape, but made it hard to appreciate the relevance to specific locations and incorporate it into project activities. An additional concern was that the Oxfam gender team had observed a lack of gender awareness and sensitivity among partner representatives, which may have prevented them from identifying gender-specific vulnerabilities.

\section{CONCLUSION}

Through the Emergency Food Security and Vulnerable Livelihoods intervention in Deir ez-Zor, Oxfam aimed to address the needs of the local population, while simultaneously positioning itself as a reliable actor for longer-term work on resilience - including more explicit work on economic and gender justice - in the area. A significant part of the intended transformation was to change gender relations around livelihoods, both to satisfy immediate needs and to maximize the opportunity for long-term change in gender relations, which are already shifting due to conflict and humanitarian crises. 
So far there have been positive outcomes, with stronger gender awareness being exhibited by local Oxfam and partner staff; adjustments to distribution processes to meet people's needs more sensitively; and strong relationships built with local organizations that will benefit future programming.

However, working in such extreme conditions is difficult and restrictive. There are still improvements to be made in undertaking assessments and programming. For example, it is not yet clear how staff should conduct accurate assessments that capture community-based conflict and power dynamics in extremely difficult circumstances. The use of remote assessments and reliable secondary sources has worked to an extent, but these could be augmented by setting up local women's workshops and engaging with local experts on a longer-term basis. The monitoring of the gender sensitivity of programming needs to be improved: this could be supported by working with local women's groups, or involving a committee of beneficiaries in project planning.

\section{NOTES}

1 OCHA. (2018). Humanitarian Needs Overview Syrian Arab Republic. https://reliefweb.int/sites/reliefweb.int/files/resources/2018 syr hno english.pdf

2 OCHA. (2018). Syria Crisis: Northeast Syria Situation Report No. 21. https://reliefweb.int/report/syrian-arab-republic/syria-crisis-northeast-syria-situationreport-no-21-1-31-january-2018

3 WFP. (2017). Nutrition Interventions: Syria 2017. https://docs.wfp.org/api/documents/WFP-0000015561/download/

4 C. Sweetman and L. Medland. (2017). Introduction: gender and water, sanitation and hygiene. Gender \& Development, 25(2), 153-66. https://policypractice.oxfam.org.uk/publications/introduction-gender-and-water-sanitation-andhygiene-620305

5 O.A. Hallaj. (2017). Who Will Own the City? Urban Housing, Land and Property Issues in Syria. Retrieved 22 August 2018 from Syrian Echoes: https://syrianechoes.com/2017/07/31/who-will-own-the-city-urban-housing-land-andproperty-issues-in-syria/

6 The response targets an estimated 53,000 of the most vulnerable women, men, boys and girls.

7 Syria Crisis Response Gender Justice Strategy (2017-21) final draft shared for internal review on February 13, 2018.

8 OCHA. (2018). Humanitarian Needs Overview Syrian Arab Republic, op. cit.

9 WFP. (2017). Nutrition Interventions: Syria 2017, op. cit. 


\section{OXFAM}

Oxfam is an international confederation of 20 organizations networked together in more than 90 countries, as part of a global movement for change, to build a future free from the injustice of poverty. Please write to any of the agencies for further information, or visit www.oxfam.org 